\section{Intracranial pressure during induction of anaesthesia and tracheal intubation with etomidate-induced EEG burst suppression}

This study was designed to determine if induction of anaesthesia with etomidate titrated to an early EEG burst suppression pattern would produce minimal changes in cerebral perfusion pressure, and prevent increases in intracranial pressure (ICP) associated with tracheal intubation. Eight patients, 18-71 yr, with intracranial space-occupying lesions, were studied. In each patient ICP was monitored via a lateral ventriculostomy catheter placed preoperatively. In the operating room, an ECG, a radial arterial line, and a two-channel computerized EEG were placed. Control (awake) measurements of $M A P(\mathrm{mmHg}), I C P(\mathrm{mmHg})$, $C P P(\mathrm{mmHg})$, heart rate (HR-bpm), EEG power (picowatts-pW), and spectral edge frequency $(S E F, H z)$ were obtained. Anaesthesia was induced with etomidate, $0.2 \mathrm{mg} \cdot \mathrm{kg}^{-1} \mathrm{iv}$, followed immediately by an etomidate infusion, $20 \mathrm{mg} \cdot \mathrm{min}^{-1}$, iv, and vecuronium $0.2 \mathrm{mg} \cdot \mathrm{kg}^{-1} \mathrm{iv}$. When early burst suppression was achieved, the etomidate infusion was stopped and tracheal intubation performed. The etomidate dose (bolus plus infusion) required to reach burst suppression was $1.28 \pm 0.11 \mathrm{mg} \cdot \mathrm{kg}^{-1}$. Compared with awake control values (mean $\pm S E$ ), the period

\section{Key words}

ANAESTHETICS, INTRAVENOUS: etomidate;

INTUBATION: endotracheal;

MEASUREMENT TECHNIQUES: blood pressure,

electroencephalography, intracranial pressure, cerebral perfusion pressure.

From the Department of Anesthesiology, Division of Neuroanesthesia, Washington University School of Medicine, Box 8054,660 S. Euclid Ave., St. Louis, MO 63110 ,

Address correspondence to: Dr. R. Tempelhoff.

Presented in part at the 1989 annual meetings of the American Society of Anesthesiologists and the Society of Neurosurgical Anesthesia and Critical Care.

Accepted for publication 4th November, 1991. from induction to burst suppression was associated with a $50 \%$ decrease in $I C P(22 \pm 1$ vs $11 \pm 1 \mathrm{mmHg}, P<0.01)$, but there were no changes in MAP, CPP, or HR. The decrease in ICP was maintained during the first $30 \mathrm{sec}$ and the following $60 \mathrm{sec}$ after intubation as MAP and HR remained unchanged. Our results suggest that when etomidate was administered to early burst suppression pattern on EEG, minimal changes in CPP occurred during induction of anaesthesia and a marked reduction in ICP was maintained following tracheal intubation.

Cette étude a été entreprise afin de déterminer si l'induction de l'anesthésie avec l'étomidate, dosé pour provoquer un début de suppression des ondes à l'EEG, produirait des changements minimes de la pression de la perfusion cérébrale, et préviendrait les augmentations de tension intracrânienne (ICP) associées à l'intubation endotrachéale. Huit patients agés de 18 à 71 ans et avec une lésion intracrânienne expansive, ont été étudiés. Dans chaque cas, la tension intracrânienne, était surveillée à l'aide d'un cathéter inséré avant la chirugie à l'aide d'une ventriculostomie latérale. Après l'installation en salle d'opération d'un ECG, d'une ligne artérielle radiale et d'un EEG informatisé à deux canaux, des mesures de contrôle (à l'état d'éveil) de la tension artérielle moyenne (MAP) $(\mathrm{mmHg})$, de la pression de la perfusion cérébrale (CPP) $(\mathrm{mmHg})$, de la fréquence cardiaque (HR-bpm), de la puissance de l'EEG (picowatts-pW) et de la fréquence de l'extrémité du spectre (" spectral edge ") (SEF, Hz) était obtenues. L'anesthésie était induite avec l'étomidate à raison de $0,2 \mathrm{mg} \cdot \mathrm{kg}^{-1} \mathrm{iv}$, suivie d'une perfusion d'étomidate à $20 \mathrm{mg} \cdot \mathrm{kg}^{-1}$ iv. et de vécuronium à $0,2 \mathrm{mg} \cdot \mathrm{kg}^{-1} \mathrm{iv}$. Lorsque la suppression des ondes de l'EEG était obtenue, la perfusion d'étomidate était cessée et on procédait à l'intubation endotrachéale. La dose d'étomidate (bolus et perfusion) requise pour supprimer les ondes à l'EEG était de $1,28 \pm 0,11 \mathrm{mg} \cdot \mathrm{kg}^{-1}$. Comparativement aux valeurs de contrôle à l'état d'êveil (moyenne $\pm S E$ ), la période entre l'induction et la suppression des ondes de l'EEG était associée à une diminution de $50 \%$ de I'ICP ( $22 \pm 1$ vs $11 \pm 1 \mathrm{mmHg}, P<0,01)$, mais il n'y avait 
aucun changement de MAP, CPP, ou HR. La diminution de l'ICP était maintenue pendant les 30 premières secondes, et une minute après l'intubation, alors que la MAP et le HR demeuraient inchangés. Nos résultats suggèrent que lorsque l'étomidate est administré et dosé jusqu'à la suppression des ondes à l'EEG, des changements minimes dans la CPP apparaissent avec l'induction de l'anesthésie et une réduction marquée de l'ICP est maintenue suite à l'intubation trachéale.

In patients with intracranial space-occupying lesions, control of mean arterial (MAP) and intracranial (ICP) pressure during anaesthetic induction and tracheal intubation is essential to prevent an untoward increase or decrease in cerebral perfusion pressure (CPP = MAP - ICP). Although thiopentone produces very favourable decreases in cerebral blood flow (CBF) and cerebral metabolic rate for oxygen $\left(\mathrm{CMRO}_{2}\right)$, ${ }^{\prime}$ large doses $\left(4-6 \mathrm{mg} \cdot \mathrm{kg}^{-1}\right.$ iv) are required to decrease ICP during induction and intubation. This "deep" level of barbiturate anaesthesia often produces marked decreases in MAP and CPP in these patients who are usually hypovolaemic as a result of fluid restriction and diuretic therapy. This decrease in MAP and CPP produced by thiopentone may result in compromised regional cerebral blood flow (rCBF). ${ }^{2}$ Conversely, "lighter" anaesthetic levels using smaller amounts $\left(2-3 \mathrm{mg} \cdot \mathrm{kg}^{-1}\right)$ of thiopentone will usually not attenuate the increases in MAP and CPP produced during laryngoscopy with tracheal intubation. ${ }^{3}$ Large increases in CPP can either increase intracranial blood volume, thereby increasing ICP, or disrupt the blood-brain-barrier (BBB), causing cerebral oedema. ${ }^{4}$

Etomidate produces comparable decreases in $\mathrm{rCBF}$, $\mathrm{CMRO}_{2},{ }^{5,6}$ and $\mathrm{ICP}^{7}$ as thiopentone. However, in contrast to the ultra-short-acting barbiturates, the usual induction doses $\left(0.2-0.3 \mathrm{mg} \cdot \mathrm{kg}^{-1} i \mathrm{v}\right)$ of etomidate produce these effects with minimal alterations in MAP or CPP. ${ }^{8}$ Similar electroencephalographic (EEG) changes have been observed following increasing doses of both induction agents. 9,10

A close relationship between etomidate blood concentrations and EEG changes has been demonstrated with a minimal time lag between peak serum concentration and effect. $9,11,12$ Thus, in contrast to the wide intersubject variability found for dose-response relationships, a closer association between the dose of etomidate administered and its resultant EEG changes can be demonstrated. ${ }^{12}$ The following study was designed to determine if induction of deep anaesthesia with etomidate, defined by an early burst suppression pattern on EEG, would decrease ICP while producing minimal changes in CPP during anaesthetic induction, and prevent the large increases in CPP and ICP after laryngoscopy and tracheal intubation.
TABLE I Aetiology of intracranial hypertension in the eight study patients

Patient 1: Obstructing hydrocephalus secondary to basilar aeneurym Patient 2: Cerebellar tumour

Patient 3: Obstructing hydrocephalus secondary to middle cerebral artery aeneurysm bleed

Patient 4: Obstructing hydrocephalus secondary to posterior communicator artery aeneurysm bleed

Patient 5: Craniopharyngioma

Patient 6: Cerebellar arterio-venous formation

Patient 7: Cerebellar tumour

Patient 8: Cerebellar tumour

\section{Methods}

Following approval of the study protocol by the Institutional Review Board of the Washington University School of Medicine, eight consenting ASA III-IV patients undergoing surgery for intracranial space-occupying lesions were studied (Table 1). Their ages ranged from 18-71 yr and each was receiving dexamethasone, $4 \mathrm{mg}$ iv every six hours. Before surgery, each patient had a lateral ventriculostomy catheter placed by the neurosurgical service for clinical and computerized tomographic (CT) scan evidence of increased ICP. Exclusion criteria included treatment with beta-adrenergic antagonists, calcium-channel antagonists, tricyclic antidepressants, monoamine oxidase (MAO) inhibitors, pregnancy, allergy to the study drugs, a functioning ventriculo-atrial or peritoneal shunt, and a history of ethanol or drug abuse. All patients were within $20 \%$ of ideal body weight $(\mathrm{kg})$.

Each patient received oral premedication with ranitidine, $150 \mathrm{mg}$, and metoclopramide, $10 \mathrm{mg}, 1-2 \mathrm{hr}$ before surgery. Upon arrival in the operating room, all patients were monitored with an ECG, automatic oscillometric blood pressure (BP) cuff (Dinamap (Ohmeda 3710), and mass spectrometer (Ohmeda 6000 Multi-Gas Monitor). A peripheral iv catheter was then inserted using local anaesthesia and a 20 -gauge radial arterial catheter was placed following the administration of fentanyl, 50-75 $\mu \mathrm{g} i v$. Both the lateral ventriculostomy and radial arterial catheters were connected to pressure transducers (Sorenson Transpac ${ }^{(T 2500-01)}$ and the pressures were recorded continuously (Mennen Horizon model \#250) following calibration.

Throughout the study period, a computerized EEG monitor (Interspec-Neurotrac ${ }^{(10)}$ ), with raw (scalp) EEG, compressed spectral array (CSA), and EEG power spectrum capabilities was employed, using a 0.5 to $30 \mathrm{~Hz}$ amplifier bandpass and a $128 \mathrm{~Hz}$ digitizing frequency. Five subdermal, fine-gauge platinum needle electrodes (Grass ${ }^{(i n)}$ ) were placed in a symmetrical frontal-temporal montage as follows. A ground electrode was placed in the middle of the forehead just superior to the nasion. Chan- 


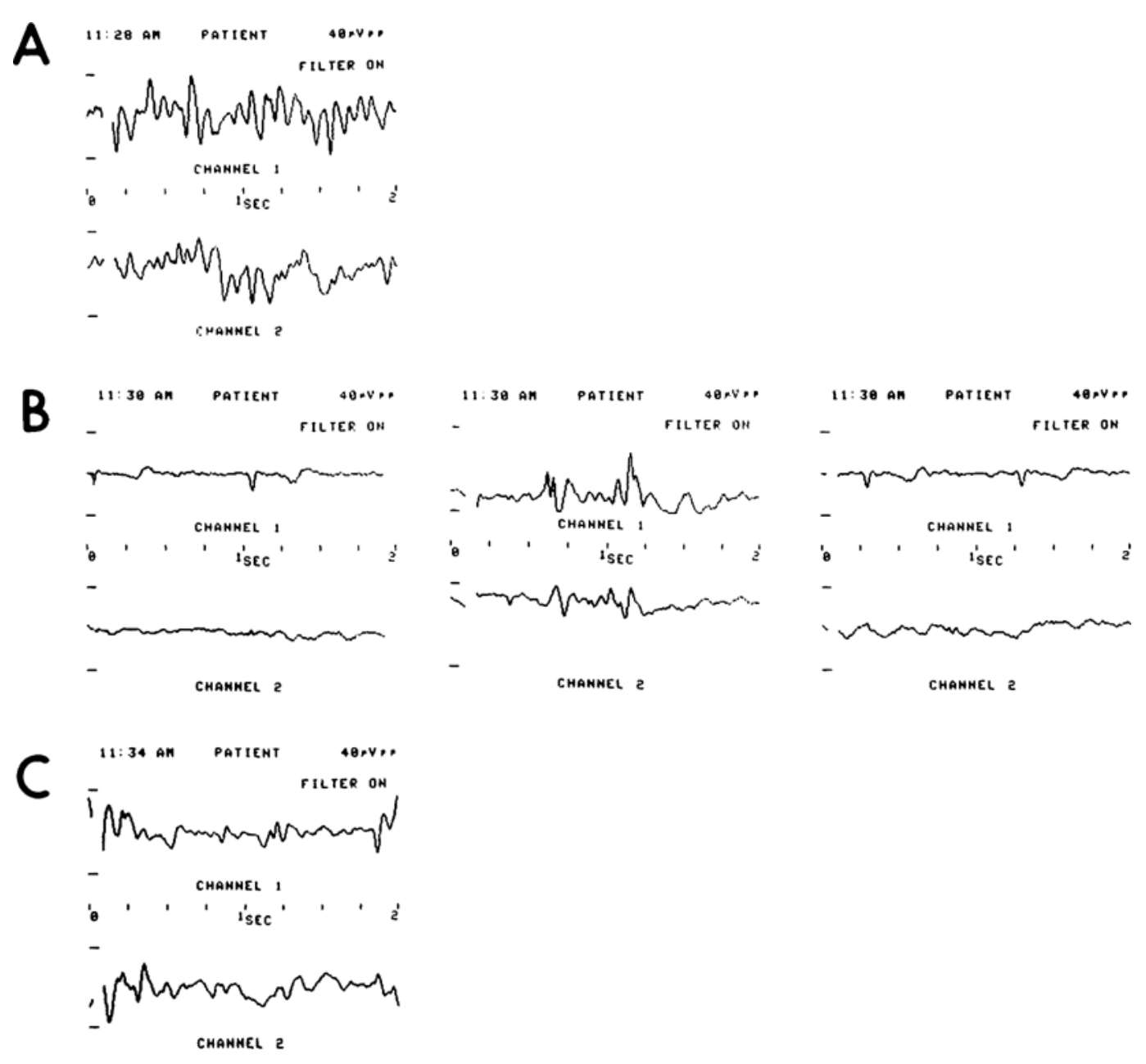

FIGURE (A) Raw EEG tracing obtained during etomidate infusion. (B) Raw EEG tracings recorded at the time of tracheal intubation. An isoelectric EEG (1) followed by a 1-2 sec burst of activity (2) is shown followed by a retum towards EEG suppression (3). (C) Raw EEG tracing recorded four minutes later is consistent with a relatively "lighter" depth of anesthesia.

nels 1 and 2 were connected by their positive (G2) terminals to left and right electrodes, placed on each side of the forehead at the lateral hairline. In addition, these two channels were connected by their negative (G1) terminals to left and right electrodes, placed on or posterior to the mastoid (this corresponds to $F_{7}-T_{5}, F_{8}-T_{6}$, in the international 10-20 system). Interelectrode distance was at least $10 \mathrm{~cm}$, and interelectrode impedence was $3 \mathrm{kOhms}$ or less. In order to produce and record satisfactory scalp EEG tracings, a sensitivity (gain) of $30-40$ microvolts $\mu v$ ) was employed. EEG power (picowatts-pW) was obtained using fast-Fourier analysis which digitizes the raw EEG signal over a 2-sec epoch into its component sine waves. Squaring the amplitudes of the individual sine waves generates the EEG power spectrum in each channel. The EEG power values from the two channels were combined and averaged for each two-second epoch for a total of 15 epochs. The
CSA display mode presents the power spectrum concisely in the form of a three-dimensional graph. With frequency of 1 to $30 \mathrm{~Hz}$ as the $\mathrm{x}$-axis, the resultant CSA with spectral edge frequency (SEF) was then displayed in 2-sec epochs. The SEF marker $(\mathrm{Hz})$ represents the frequency below which $95 \%$ of the EEG power is located.

Control (awake) measurements of MAP, ICP, CPP, HR, EEG power, and SEF were obtained just before anaesthetic induction and CPP was calculated. These six baseline variables were measured during a period of low patient stimulation and were stable for at least one min prior to their recording. With each patient receiving $100 \%$ oxygen $\left(\mathrm{O}_{2}\right)$ by mask, anaesthesia was induced with etomidate, 0.2 $\mathrm{mg} \cdot \mathrm{kg}^{-1} i v$, followed by a continuous iv etomidate infusion at a rate of $20 \mathrm{mg} \cdot \mathrm{min}^{-1}$. During the study, continuous scalp (raw) EEG, EEG power, and CSA with SEF recordings were obtained and interpreted by an anaesthe- 
TABLE II Mean arterial pressure (MAP), intra-cranial pressure (ICP), cerebral perfusion pressure (CPP), heart rate (HR), EEG power, and EEG spectral edge frequency (SEF) during induction of anaesthesia and tracheal intubation

\begin{tabular}{lllll}
\hline & & $\begin{array}{l}\text { Induction } \\
\text { to burst } \\
\text { suppression }\end{array}$ & $\begin{array}{l}\text { 1-30 sec } \\
\text { postintubation }\end{array}$ & $\begin{array}{l}31-90 \mathrm{sec} \\
\text { postintubation }\end{array}$ \\
\hline MAP (mmHg) & $93 \pm 3$ & $89 \pm 3$ & $93 \pm 3$ & $94 \pm 3$ \\
ICP (mmHg) & $22 \pm 1$ & $11 \pm 1^{*}$ & $11 \pm 1^{*}$ & $11 \pm 1^{*}$ \\
CPP (mmHg) & $72 \pm 2$ & $78 \pm 2^{*}$ & $82 \pm 2^{*}$ & $83 \pm 2^{*}$ \\
HR (bpm) & $86 \pm 2$ & $88 \pm 2$ & $92 \pm 2$ & $92 \pm 2$ \\
EEG power (pW) & $94 \pm 8$ & $25 \pm 8^{*}$ & $26 \pm 8^{*}$ & $27 \pm 8^{*}$ \\
SEF Hz & $23 \pm 1$ & $12 \pm 1^{*}$ & $13 \pm 1^{*}$ & $13 \pm 1^{*}$ \\
\hline
\end{tabular}

All values are mean $\pm \mathrm{SE}$.

$* P<0.01$ vs awake control values.

tist who was unaware of the etomidate dose administered. When there was no response to verbal and tactile stimulation, vecuronium $0.2 \mathrm{mg} \cdot \mathrm{kg}^{-1} \mathrm{iv}$, was given, and ventilation was controlled by mask using $100 \% \mathrm{O}_{2}$ to maintain end-tidal $\mathrm{PCO}_{2}$ of $35-40 \mathrm{mmHg}$ with an $\mathrm{O}_{2}$ saturation of 98-100\%. From the start of induction until an early EEG burst suppression pattern was reached, the lowest values for MAP, ICP, CPP, HR, EEG power, and SEF were recorded. If $>30 \%$ decrease in MAP occurred during this time, the etomidate infusion was to be stopped, and ephedrine, 5-10 $\mathrm{mg} i v$, given.

When an early burst suppression pattern, characterized by an isoelectric raw EEG separated by 1-2-sec bursts of electrical activity recorded at a sensitivity of $30-40 \mu v$; was achieved (Figure), the etomidate infusion was stopped, tracheal intubation performed, and $100 \% \mathrm{O}_{2}$ administered. The highest values for MAP, ICP, CPP, HR, EEG power, and SEF were recorded during the first $30 \mathrm{sec}$ immediately after laryngoscopy and intubation. The peak values of these six variables were again recorded during the following $60 \mathrm{sec}$. If $>30 \%$ increase in MAP occurred shortly after intubation, it was treated with labetalol $5 \mathrm{mg}$ $i v$. The time from the initial etomidate bolus until burst suppression occurred was noted, as was the total dose of etomidate required to reach burst suppression. In addition, the durations of laryngoscopy and burst suppression were recorded. When burst suppress ion was no longer present, maintenance of anaesthesia using controlled ventilation was begun with nitrous oxide $60-70 \%\left(\mathrm{~N}_{2} \mathrm{O}\right)$ in $\mathrm{O}_{2}$, isoflurane ( $0.1-0.3 \%$ end-tidal), and a fentanyl infusion (1-2 $\left.\mu \mathrm{g} \cdot \mathrm{kg}^{-1} \cdot \mathrm{hr}^{-1}\right)$.

All measures are reported as mean $\pm \mathrm{SE}$. The findings for MAP, ICP, CPP, HR, EEG power, and SEF recorded during the periods of: (1) induction to burst suppression; (2) 1-30 sec following intubation; and (3) 31-90 see following intubation, were compared with their control (awake) measurements using analysis of variance with repeated measures. A $P<0.05$ was considered significant.

\section{Results}

The mean age and weight of the eight patients studied were $39 \pm 9 \mathrm{yr}$ and $58 \pm 5 \mathrm{~kg}$, respectively. The MAP, ICP, CPP, HR, EEG power, and SEF findings are summarized in Table II. Compared with the awake control measures, the period from induction to burst suppression was associated with $\geq 50 \%$ decreases in ICP ( $22 \pm 1$ vs 11 $\pm 1 \mathrm{mmHg}, P<0.01)$, EEG power $(94 \pm 8$ vs $25 \pm 8 \mathrm{pW}$, $P<0.01)$, and SEF ( $23 \pm 1$ vs $12 \pm 1 \mathrm{~Hz}, P<0.01)$, but did not produce any changes in MAP or HR. These decreases in ICP, EEG power, and SEF were maintained during the first $30 \mathrm{sec}$ and the subsequent $60 \mathrm{sec}$ after intubation as MAP and HR remained unchanged. The findings for ICP and MAP resulted in increases in CPP during the period from induction to burst suppression (72 \pm 2 vs $82 \pm 2 \mathrm{mmHg}, P<0.01)$ plus the 30 - and subsequent 60 -sec $(72 \pm 2$ vs $83 \pm 2 \mathrm{mmHg}, P<0.01)$ measurement periods after intubation, when these values for CPP were compared with awake controls. However, further analysis did not reveal any changes in these $90-\mathrm{sec}$ post-intubation CPP values ( $78 \pm 2$ vs $82-83 \pm 2 \mathrm{mmHg}$, $P=$ NS) when they were compared with the lowest CPP recorded during the period from induction to burst suppression. None of the patients required treatment for increases or decreases in MAP > 30\% during either induction of anaesthesia or following tracheal intubation.

Burst suppression on EEG was reached in $240 \pm 33 \mathrm{sec}$ and its duration was $211 \pm 25 \mathrm{sec}$ (Table III). Duration of laryngoscopy was $20 \pm 1.8 \mathrm{sec}$. The etomidate dose required to reach burst suppression was $1.28 \pm 0.11$ $\mathrm{mg} \cdot \mathrm{kg}^{-1}$.

\section{Discussion}

Except for ketamine, ${ }^{13.14}$ all iv anaesthesia induction agents decrease ICP. ${ }^{7,15-17}$ Unfortunately, aside from etomidate, ${ }^{7}$ the dosages required to decrease ICP often produce large decreases in MAP that can lead to considerable reductions in CPP ${ }^{2,16,17}$ which may jeopardize collat- 
eral blood supply to ischaemic regions of the brain. Conversely, tracheal intubation in patients with reduced intracranial compliance (e.g., tumour, haemorrhage, etc.) commonly produces large increases in ICP and CPP which can lead to a worsening of neurological status. Unfortunately, the efficacy of all anaesthetic induction agents, including etomidate in the usual $\left(0.2-0.3 \mathrm{mg} \cdot \mathrm{kg}^{-1}\right)$ dosage, in preventing an increase in ICP during laryngoscopy and intubation has not been demonstrated. 2,7,13,15-17 In our report, using a standard etomidate induction dose followed by a controlled infusion, ICP decreased and CPP was maintained throughout induction. These results were not surprising and are consistent with earlier findings for etomidate.,18,19 However, more importantly, using an early burst suppression pattern on EEG as the endpoint for etomidate administration as well as an indicator of "deep anaesthesia," we were able to maintain a marked reduction in ICP following laryngoscopy and intubation. Furthermore, compared with the findings recorded during the period from induction to burst suppression, this etomidate-induced EEG effect also prevented an intubation-associated increase in CPP while probably producing favourable decreases in $\mathrm{CMRO}_{2}$ and CBF. $^{5,20}$

Because the EEG is an indicator of the electrical activity of the cerebral cortex, it may provide a continuous, sensitive measure of the degree of drug-induced cerebral depression (depth of anaesthesia) prior to noxious stimuli. If so, the degree of EEG depression may then be used to predict the magnitude of the intracranial and/or haemodynamic pressure response following laryngoscopy and endotracheal intubation. However, previous attempts at correlating various EEG measures and haemodynamic responses have yielded inconsistent results. ${ }^{12,21-23}$ The inconsistent findings for the SEF may be related to its large decline during light levels of anaesthesia which overshadows its subsequent decreases during deepening of anaesthesia. ${ }^{12.23}$ Thus, the compression of the EEG voltage waveform produced by the SEF is at the expense of information regarding the slower EEG waveforms more prevalent at the deeper levels of anaesthesia. ${ }^{21,23}$ Arden $e t$ al. ${ }^{12}$ found the median EEG frequency to be a better measure of etomidate's EEG effects. Unfortunately, they also frequently saw hypertension which was not associated with EEG signs of arousal. Finally, in a recent report ${ }^{23}$ using a sufentanil infusion for induction, failure to respond to verbal commands was found to coincide with a ceiling effect for various processed EEG variables (SEF, mean frequency, power spectrum), and little further changes in EEG activity were demonstrated despite the continued deepening of anaesthesia with sufentanil.

It is possible that the intracranial and haemodynamic responses to stimuli like tracheal intubation are more
TABLE III Time to dose requirement and duration of EEG burst suppression produced by etomidate

\begin{tabular}{ll}
\hline Time from etomidate bolus until & \\
EEG burst suppression: & $240 \pm 33 \mathrm{sec}$ \\
$\begin{array}{l}\text { Etomidate dose (bolus plus infusion) } \\
\text { to reach burst suppression: }\end{array}$ & $1.28 \pm 0.11 \mathrm{mg} \cdot \mathrm{kg}^{-1}$ \\
Total duration of burst suppression: & $211 \pm 25 \mathrm{sec}$ \\
\hline
\end{tabular}

closely related to neurophysiological events in the lower subcortical CNS structures (i.e.: brain stem) rather than cortical events, which would more likely be reflected by processed EEG variables such as the SEF or median frequency. ${ }^{22}$ Thus, because these computerized EEG variables primarily reflect cerebral cortical activity, deeper levels of anaesthetic-induced CNS (EEG) depression appear to be necessary to obtund the stress response to laryngoscopy and intubation. Burst suppression on EEG appears to correlate with the onset of pontine depression. ${ }^{24}$ In view of this association between burst suppression and brainstem depression plus the inconsistent relationship between various processed EEG variables and $B P$, we decided to determine if an early burst suppression pattern on EEG produced by etomidate would obtund the intracranial and cerebral perfusion pressure responses to tracheal intubation. The results of this study support the efficacy of our EEG-based model which maintained a decrease in ICP and produced minimal changes in CPP despite the stress of laryngoscopy and intubation.

Previous studies demonstrated that there is no simple method to maintain a decreased ICP (compared with its awake baseline value) immediately following laryngoscopy and tracheal intubation in patients with intracranial hypertension. Although thiopentone, ${ }^{2}$ lidocaine, ${ }^{25}$ and propofol $^{17}$ are all beneficial in attenuating the increase in ICP secondary to tracheal stimulation, none has been shown to maintain a decreased ICP effectively soon after intubation. In our report, using early EEG burst suppression as the endpoint for etomidate administration, a large reduction in ICP occurred which, to our knowledge, was maintained for the first time following laryngoscopy and intubation. In addition, our controlled method of etomidate administration probably also contributed to the prevention of an induction-associated fall in CPP, a problem frequently encountered with other commonly employed $i v$ anaesthetic induction agents which lower ICP, especially when administered in a bolus fashion. ${ }^{2,16,17.26}$

In summary, when etomidate was administered to an early EEG, burst suppression pattern ICP was decreased and minimal changes in CPP occurred during induction of anaesthesia. Using this EEG pattern as an indicator of "deep anaesthesia" the reduction in ICP was maintained after laryngoscopy and tracheal intubation. This EEG- 
based model for etomidate administration may represent an improved anaesthetic induction technique for patients with intracranial hypertension.

\section{Acknowledgement}

The authors would like to thank Edward L. Spitznagel, Jr, $\mathrm{PhD}$ for his help with data analysis.

\section{References}

1 Stullken EH Jr, Milde JH, Michenfelder JD, Tinker JH. The nonlinear responses of cerebral metabolism to low concentrations of halothane, enflurane, isoflurane, and thiopental. Anesthesiology 1977; 46: 28-34.

2 Moss E, Powell D, Gibson RM, McDowall DG. Effects of tracheal intubation on intracranial pressure following induction of anaesthesia with thiopentone or althesin in patients undergoing neurosurgery. Br J Anaesth 1978; 50: 353-60.

3 Unni VKN, Johnston RA, Young HSA, McBride RJ. Prevention of intracranial hypertension during laryngoscopy and endotracheal intubation. Use of a second dose of thiopentone. Br J Anaesth 1984; 56: 1219-23.

4 Messick JM Jr, Newberg LA, Nugent M, Faust RJ. Principles of neuroanesthesia for the nonneurosurgical patient with CNS pathophysiology. Anesth Analg 1985; 64: 143-74.

5 Renou AM, Vernhiet J, Macrez $P$, et al. Cerebral blood flow and metabolism during etomidate anaesthesia in man. Br J Anaesth 1978; 50: 1047-51.

6 Cold GE, Eskesen V, Eriksen H, Blatt Lyon B. Changes in $\mathrm{CMRO}_{2}, \mathrm{EEG}$, and concentration of etomidate in serum and brain tissue during craniotomy with continuous etomidate supplemented with $\mathrm{N}_{2} \mathrm{O}$ and fentanyl. Acta Anaesthesiol Scand 1986; 30: 159-63.

7 Moss E, Powell D, Gibson RM, McDowall DG. Effect of etomidate on intracranial pressure and cerebral perfusion pressure. Br J Anaesth 1979; 51: 347-52.

8 Giese JL, Stanley TH. Etomidate: a new intravenous anesthetic induction agent. Pharmacotherapy $1983 ; 3: 251-8$.

9 Doenicke A, Loffler B, Kugler J, Suttmann H, Grote $B$. Plasma concentration and EEG after various regimens of etomidate. Br J Anaesth 1982; 54: 393-400.

10 Ghoneim $M M$, Yamada $T$. Etomidate: a clinical and electroencephalographic comparison with thiopental. Anesth Analg 1977; 56: 479-85.

11 Freye E, Hartung E, Klatte A, Abel J. Plasma levels of alfentanil and etomidate in patients and their relation to compressed power spectral analysis of the EEG. Acta Anaesthesiologica Belgica 1983; 12: 87-96.

12 Arden JR, Holley FO, Stanski DR. Increased sensitivity to etomidate in the elderly: initial distribution versus altered brain response. Anesthesiology 1986; 65: 19-27.

13 Gardner AE, Olson BE, Lichtiger $M$. Cerebrospinal fluid pressure during dissociative anesthesia with ketamine Anesthesiology $1971 ; 35: 226-31$.

14 Takeshita H, Okuda Y, Sari A. The effects of ketamine on cerebral circulation and metabolism in man. Anesthesiology 1972; 36: 69-74.

15 Shapiro HM, Galindo A, Wyte SR, Harris AB. Rapid intraoperative reduction of intracranial pressure with thiopentone. Br J Anaesth 1973; 45: 1057-62.

16 Hunter $A R$. Methohexitone as a supplement to nitrous oxide during intracranial surgery. $\mathrm{Br} \mathrm{J}$ Anaesth 1972; 44: 1188-93.

17 Ravussin P, Guinard JP, Ralley F, Thorin D. Effect of propofol on cerebrospinal fluid pressure and cerebral perfusion pressure in patients undergoing craniotomy. Anaesthesia 1988; 43 (Suppl): 37-41.

18 Cunitz $G$, Danhauser I, Wickbold J. Comparative investigations on the influence of etomidate, thiopentone and methohexitone on the intracranial pressure of the patient. Anaesthetist 1978; 27: 64-70.

19 Schulte AM, Esch J, Pfeifer G, Thiemig I. Effects of etomidate and thiopentone on the primarily elevated intracranial pressure (ICP). Anaesthetist 1978; 27: 71-5.

20 Wauquier $A$. Brain protective properties of etomidate and flumorizine. J Cereb Blood Flow Metab 1982; 2: 53-6.

21 Rampil IJ, Matteo RS. Changes in EEG spectral edge frequency correlate with the hemodynamic response to laryngoscopy and intubation. Anesthesiology 1987; 67: 139-42.

22 White $P F$, Boyle WA. Relationship between hemodynamic and electroencephalographic changes during general anesthesia. Anesth Analg 1989; 68: 177-81.

23 Chi OZ, Sommer $W$, Jasaitis $D$. Power spectral analysis of EEG during sufentanil infusion in humans. Can J Anaesth 1991; 38: 275-80.

24 Pichlmayr I, Lips $U$, Kunkel H. Stages of anesthesia. In: Pichlmayr I, Lips U, Kunkel H (Eds.). The Electroencephalogram in Anesthesia. Berlin: Springer-Verlag, 1984; 65-71.

25 Hamill JF, Bedford RF, Weaver DC, Colohan AR. Lidocaine before endotracheal intubation: intravenous or laryngotracheal? Anesthesiology 1981; 55: 578-81.

26 Griffin JP, Cottrell JE, Shwiry B, Hartung J, Epstein J, Lim $K$. Intracranial pressure, mean arterial pressure, and heart rate following midazolam or thiopental in humans with brain tumors. Anesthesiology 1984; 60: 491-4. 